\title{
Intra-arterial versus standard intravenous administration of lutetium-177-DOTA- octreotate in patients with NET liver metastases: study protocol for a multicenter, randomized controlled trial (LUTIA trial)
}

Sander C. Ebbers, Arthur J. A. T. Braat, Adriaan Moelker, Marcel P. M. Stokkel, Marnix G. E. H. Lam and Maarten W. Barentsz

\begin{abstract}
Background: Lutetium-177-DOTA-octreotate ( ${ }^{177}$ Lu-DOTATATE) significantly increases survival and response rates in patients with grade I and grade II neuroendocrine tumors (NETs). However, survival and response rates are significantly lower in patients with bulky liver metastases. Increasing the tumor-absorbed dose in liver metastases may improve response to ${ }^{177}$ Lu-DOTATATE. The LUTIA (Lutetium Intra-Arterial) study aims to increase the tumor-absorbed dose in liver metastases by intra-arterial (IA) administration of ${ }^{177}$ Lu-DOTATATE, compared to conventional intravenous (IV) administration.
\end{abstract}

Methods: A multicenter, within-patient randomized controlled trial $(\mathrm{RCT})$ in 26 patients with progressive, liverdominant, unresectable grade I or grade II NET will be conducted. Patients with bilobar bulky disease will be randomly allocated to receive IA treatment into either the left or the right hepatic artery. Using this approach, one liver lobe will be treated intra-arterially (first-pass effect), while the contralateral lobe will receive an intravenous treatment as a second-pass effect. The primary endpoint of this study is the difference in tumor-to-non-tumor ratio of ${ }^{177} \mathrm{Lu}$ DOTATATE uptake between the two liver lobes on post-treatment SPECT/CT (IA versus IV). Secondary endpoints include absorbed dose in both liver lobes, tumor response, dose-response relationship, toxicity, uptake in extrahepatic lesions, and renal uptake.

Discussion: This multicenter, within-patient RCT will investigate whether IA administration of ${ }^{177}$ Lu-DOTATATE results in a higher activity concentration in liver metastases compared to IV administration.

Trial registration: ClinicalTrials.gov, NCT03590119. Registered on 17 July 2018.

Keywords: Intra-arterial, PRRT, NET, Neuroendocrine tumor, Neuroendocrine neoplasm, Lutetium-177-DOTATATE, ${ }^{177}{ }^{\text {Lu- }}$ DOTATATE

\footnotetext{
* Correspondence: m.barentsz@umcutrecht.nl

Department of Radiology and Nuclear Medicine, University Medical Center

Utrecht, Heidelberglaan 100, 3584 CX Utrecht, The Netherlands
}

(c) The Author(s). 2020 Open Access This article is distributed under the terms of the Creative Commons Attribution 4.0 International License (http://creativecommons.org/licenses/by/4.0/), which permits unrestricted use, distribution, and 


\section{Background}

Peptide receptor radionuclide therapy (PRRT) with lutetium-177-DOTA-octreotate $\quad\left({ }^{177} \mathrm{Lu}\right.$-DOTATATE; Lutathera, Advanced Accelerator Applications, SaintGenis-Pouilly, France) is the standard treatment for inoperable metastasized grade I and grade II gastrointestinal neuroendocrine tumors (NETs) [1]. Grade I and grade II NETs are well or moderately differentiated tumors. However, metastatic disease at initial diagnosis is present in approximately $50 \%$ of patients $[2,3]$. The liver is the most frequently affected site of metastases, followed by the peritoneum, bone, lung, and ovary [4]. In order to control disease progression, to achieve symptomatic relief, and to prolong survival, PRRT is increasingly used in the treatment of progressive NETs $[5,6] .{ }^{177}$ Lu-DOTATATE is a radiopharmaceutical, consisting of a somatostatin-analog peptide labeled with an isotope with a high-energy beta emission, that binds with high affinity to the somatostatin receptor subtype 2 (SSTR-2), overexpressed in grade I and II NET cells $[7,8] .{ }^{177}$ Lu-DOTATATE significantly increases progression-free survival (PFS) and overall survival (OS), with limited toxicity, compared to non-radioactive high-dose somatostatin analogs in patients with advanced stage NET [5, 6, 9-11].

However, patients with liver metastases have a significantly lower PFS, even after ${ }^{177} \mathrm{Lu}$-DOTATATE treatment $[12,13]$. A post hoc analysis of the NETTER-1 trial showed that the presence of bulky lesions $(>3 \mathrm{~cm})$ was significantly associated with a worse PFS after PRRT [14].

To improve the absorption and binding of the radiopharmaceutical to NET cells, small studies have evaluated the effect of intra-arterial (IA) administration of several different radiopharmaceuticals (e.g., ${ }^{177} \mathrm{Lu}$-DOTATATE, ${ }^{90}$ Y-DOTATOC, etc.) into the common hepatic artery [15]. Tumor-absorbed doses seemed to be higher after IA administration of the radiopharmaceutical, but comparative studies have not been performed [15].

The current study compares IA administration of ${ }^{177} \mathrm{Lu}$-DOTATATE with intravenous (IV) administration. This manuscript provides a detailed description of the study protocol.

\section{Methods}

\section{Hypothesis}

The hypothesis is that IA administration of ${ }^{177} \mathrm{Lu}$ DOTATATE into the hepatic artery will result in a higher tumor-to-non-tumor $(\mathrm{T} / \mathrm{N})$ uptake ratio, compared to IV administration.

\section{Trial design}

The Lutetium Intra-Arterial (LUTIA) study is a multicenter, open-label, phase II, within-patient RCT. The study design differs from the standard parallel-group design, in which patients are allocated by randomization to either the treatment or the control group [16]. Instead, patients will act as their own control, by treating only half of the liver by IA administration of ${ }^{177} \mathrm{Lu}$ DOTATATE. Via the systemic circulation, the contralateral lobe and extrahepatic disease will be treated as if by IV administration (second-pass effect; see Fig. 1). ${ }^{177} \mathrm{Lu}$ DOTATATE activity in tumors in the IA-treated lobe will be compared with the activity in tumors in the contralateral lobe (IV-treated).

The study will be conducted in accordance with the Declaration of Helsinki and current guidelines of Good Clinical Practice. The current research protocol has been approved by the central Research Ethics Committee of the University Medical Center Utrecht (reference approval number 17-446), and we will not begin recruiting at other centers in the trial until local ethical approval has been obtained. The study protocol has also been approved by the radiation protection committees of the participating centers (i.e., University Medical Center Utrecht, Erasmus Medical Center Rotterdam, Antoni van Leeuwenhoek Amsterdam). A Standard Protocol Items: Recommendations for Interventional Trials (SPIRIT) checklist is provided in Additional file 1. Figure 2 shows the schedule of interventions and assessments [17].

\section{Subjects}

All patients with World Health Organization (WHO) grade I or II NET, originating from gastric, enteric, or pancreatic origin with hepatic metastases and an indication for PRRT are eligible for inclusion. The total hepatic burden should be estimated to involve at least $25 \%$ of the liver volume, with a minimum of one lesion of at least 3 $\mathrm{cm}$ in size in each liver lobe on cross-sectional imaging. A size of at least $3 \mathrm{~cm}$ is required for reliable measurement of activity on single photon emission computed tomography (SPECT)/computed tomography (CT).

\section{Recruitment}

Patients will be recruited in three centers (European Neuroendocrine Tumor Society [ENETS] Centers of Excellence) in The Netherlands. During a multidisciplinary tumor board, patients will be reviewed for eligibility to participate in the study. Study information will be provided by the study physician, nuclear medicine physician, or oncologist/endocrinologist. General inclusion and exclusion criteria for PRRT, as described in the ENETS guidelines, will be applied (Table 1) [1, 18].

\section{Study procedures}

\section{Screening}

At baseline, demographic data, medical history, medication usage, current complaints, physical examination, and WHO performance status will be recorded 


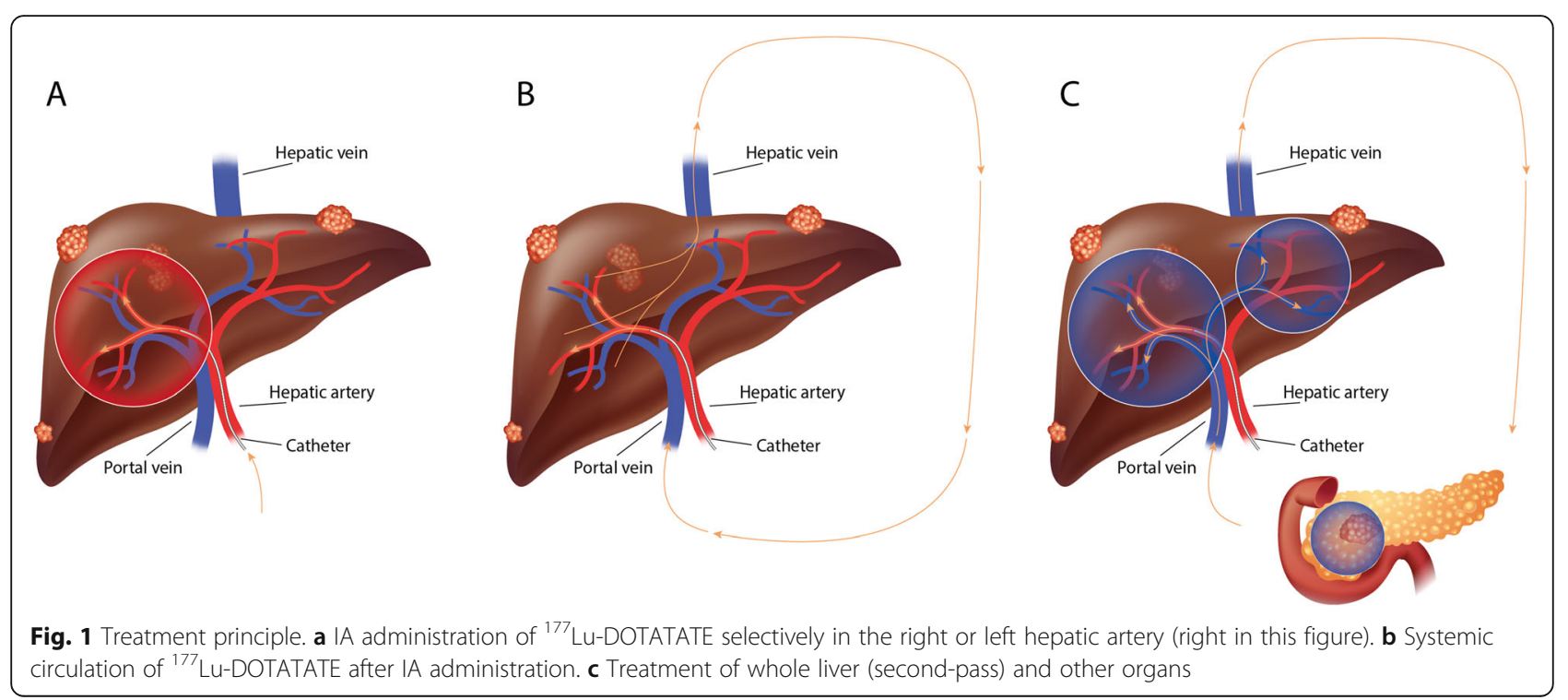

\begin{tabular}{|c|c|c|c|c|c|c|}
\hline & \multicolumn{6}{|c|}{ Study period } \\
\hline & $\begin{array}{c}\text { Pre- } \\
\text { randomizati } \\
\text { on }\end{array}$ & Allocation & $\begin{array}{c}\text { Treatment } \\
(4 \mathrm{x})\end{array}$ & $\begin{array}{l}\text { Control- } \\
\text { visit }(4 \mathrm{x})\end{array}$ & $\begin{array}{l}\text { Follow-up } \\
\text { (3 months) }\end{array}$ & $\begin{array}{l}\text { Follow- } \\
\text { up/close- } \\
\text { out (6 } \\
\text { months) }\end{array}$ \\
\hline \multicolumn{7}{|l|}{ Enrolment } \\
\hline Written informed consent & $x$ & & & & & \\
\hline In-/exclusion criteria & $x$ & & & & & \\
\hline Randomization left/right & & $x$ & & & & \\
\hline \multicolumn{7}{|l|}{ Interventions } \\
\hline $\begin{array}{l}\text { Pregnancy test for women of } \\
\text { childbearing age }\end{array}$ & & & $x$ & & & \\
\hline Antiemetic premedication & & & $x$ & & & \\
\hline Infusion of amino acids & & & $x$ & & & \\
\hline Angiography & & & $x$ & & & \\
\hline Administration of treatment dose & & & $x$ & & & \\
\hline \multicolumn{7}{|l|}{ Assessments } \\
\hline Demographic data & $x$ & & & & & \\
\hline Medical history & $x$ & & & & & \\
\hline $\begin{array}{l}\text { Previous and on-going (concomitant) } \\
\text { medication }\end{array}$ & $x$ & & $x$ & $x$ & $x$ & $x$ \\
\hline $\begin{array}{l}\text { Physical exam, vital signs and clinical } \\
\text { performance status (ECOG) }\end{array}$ & $x$ & & $x$ & $x$ & $x$ & $x$ \\
\hline Contrast-enhanced CT & $x$ & & & & $x$ & $x$ \\
\hline Somatostatine-receptor imaging & $x$ & & & & $x$ & $x$ \\
\hline Laboratory examination & $x$ & & $x$ & $x$ & $x$ & $x$ \\
\hline $\begin{array}{l}\text { SPECT/CT ( } 24 \pm 3 \text { hours after } \\
\text { treatment) and total-body planar } \\
\text { imaging }\end{array}$ & & & $x$ & & & \\
\hline $\begin{array}{l}\text { Monitoring of occurrence of (serious) } \\
\text { adverse events }\end{array}$ & & & $x$ & $x$ & $x$ & $x$ \\
\hline
\end{tabular}

Fig. 2 SPIRIT figure showing all phases of the trial, including the interventions and assessment time points 
Table 1 Detailed inclusion and exclusion criteria

\begin{tabular}{|c|c|}
\hline Inclusion criteria & Exclusion criteria \\
\hline Patients must have given written informed consent & $\begin{array}{l}\text { Any previous radioembolization, chemoembolization, bland embolization, or external } \\
\text { beam radiation therapy to the liver, at any time, or surgery or radiofrequency ablation (or } \\
\text { other ablative therapies) within } 12 \text { weeks prior to randomization in the study }\end{array}$ \\
\hline Male or female aged 18 years or older & $\begin{array}{l}\text { Interferons, everolimus (mTOR-inhibitors), or other systemic therapies within } 4 \text { weeks prior } \\
\text { to randomization in the study }\end{array}$ \\
\hline $\begin{array}{l}\text { Inoperable histologically proven neuroendocrine tumor } \\
\text { with an indication for }{ }^{177} \text { Lu-DOTATATE }\end{array}$ & $\begin{array}{l}\text { Use of octreotide or octreotide LAR, if it cannot be interrupted for } 24 \mathrm{~h} \text { or } 4 \text { weeks before } \\
\text { therapy, respectively, unless tumor uptake on somatostatin receptor imaging is higher } \\
\text { than normal liver uptake }\end{array}$ \\
\hline Ki- 67 index $\leq 20 \%$ and a mitotic count of $\leq 20$ & Unresolved toxicity from previous anti-cancer therapy greater than grade 2 \\
\hline $\begin{array}{l}\text { Confirmed presence of somatostatin receptors on target } \\
\text { lesions }\end{array}$ & Serum bilirubin $>$ upper limit of normal (ULN), serum albumin $<3.0 \mathrm{~g} / \mathrm{dL}$ \\
\hline Life expectancy of 6 months or longer & Glomerular filtration rate $<50 \mathrm{ml} / \mathrm{min}$ \\
\hline $\begin{array}{l}\text { Eastern Cooperative Oncology Group (ECOG) } \\
\text { performance score } 0-1\end{array}$ & $\begin{array}{l}\mathrm{Hb}<5.5 \mathrm{mmol} / \mathrm{L} \text {; leucocytes }<3.0 \times 10^{9} / \mathrm{L} \text {; platelets }<100 \times 10^{9} / \mathrm{L} \text { (at baseline; } 75 \times 10^{9} / \mathrm{L} \text { is } \\
\text { sufficient for cycles } 2-4 \text { ) }\end{array}$ \\
\hline $\begin{array}{l}\text { At least one lesion } \geq 3 \mathrm{~cm} \text { on cross-sectional imaging in } \\
\text { both the right and left liver lobes }\end{array}$ & Uncontrolled congestive heart failure or diabetes mellitus \\
\hline $\begin{array}{l}\text { Presence of excessive liver metastases, defined as }>25 \% \\
\text { tumor burden }\end{array}$ & Patients suffering from diseases with an increased chance of liver toxicity \\
\hline $\begin{array}{l}\text { Patients must have clinical or radiological progressive } \\
\text { disease }\end{array}$ & $\begin{array}{l}\text { Patients declared incompetent or suffering from psychic disorders making comprehensive } \\
\text { judgement impossible }\end{array}$ \\
\hline \multirow{6}{*}{$\begin{array}{l}\text { Negative pregnancy test for women of childbearing } \\
\text { potential }\end{array}$} & Previous enrollment in the present study or previous treatment with ${ }^{177}$ Lu-DOTATATE \\
\hline & $\begin{array}{l}\text { Female patients who are not using an acceptable method of contraception, OR are less } \\
\text { than } 1 \text { year postmenopausal or surgically sterile }\end{array}$ \\
\hline & $\begin{array}{l}\text { Male patients who are not surgically sterile or do not use an acceptable method of } \\
\text { contraception }\end{array}$ \\
\hline & Body weight more than $150 \mathrm{~kg}$ \\
\hline & Current spontaneous urinary incontinence \\
\hline & Severe allergy for intravenous contrast \\
\hline
\end{tabular}

(Fig. 3). Furthermore, patients will undergo the following investigations: ${ }^{68}$ Ga-labeled somatostatin analog positron emission tomography/computed tomography $\left({ }^{68} \mathrm{Ga}-\mathrm{SSTR}\right.$ PET/CT) to ascertain sufficient somatostatin receptor expression; contrast-enhanced diagnostic CT of the liver to acquire hepatic tumor size and location; laboratory investigations to assess the general condition and presence of toxicity (i.e., liver enzyme and bilirubin levels, coagulation tests, kidney function, and hematologic tests).

\section{Treatment}

After providing informed consent, patients will be randomized to IA treatment of either the left or the right liver lobe. A complete treatment consists of four cycles of ${ }^{177} \mathrm{Lu}$-DOTATATE every 6 to 12 weeks [18]. On the day of treatment, patients will be hospitalized for one day and one night. Laboratory examination will be performed to ensure no toxicities have occurred and that the patient is fit for treatment and angiography. Prior to or at the start of the angiography procedure, co-infusion of amino acids ( $1 \mathrm{~L} 2.5 \%$ lysine/arginine during $4 \mathrm{~h}$ ) is initiated and prophylactic oral anti-emetics (ondansetron
$8 \mathrm{mg}$ ) are given. During the angiography, the allocated hepatic artery (i.e., left or right) will be catheterized via a femoral or radial approach. A nuclear medicine physician and interventional radiologist will determine the final injection position during angiography. In the first angiographic procedure, a cone-beam computed tomography $(\mathrm{CBCT})$ scan will be performed with a catheter position identical to the injection position. The CBCT confirms the target tumor's arterial blood supply and demonstrates the arteries' perfusion territory. Next, $7400 \mathrm{MBq}$ of ${ }^{177} \mathrm{Lu}$-DOTATATE is administered in 30 min, according to the instructions for use of Lutathera [19]. During every cycle, the same injection position is used (i.e., the same randomly allocated liver lobe is IAtreated four times).

All (serious) adverse events will be monitored and logged by medical personnel. A post-treatment ${ }^{177} \mathrm{Lu}-$ DOTATATE SPECT/CT scan and total-body planar scintigraphy will be acquired $24 \mathrm{~h}( \pm 3 \mathrm{~h})$ post-injection. The acquisition of the SPECT/CT scan after the first cycle is essential for the main study objective, while the SPECT/ CT scans after the second, third, and fourth cycles will provide information on the secondary study objectives. 




Fig. 3 Study procedures in the LUTIA trial

\section{Follow-up}

A control visit will be scheduled 4 to 7 weeks after each administration. At 3 and 6 months after completion of all four cycles, a control visit is scheduled and a contrast-enhanced diagnostic $\mathrm{CT}$ in combination with a ${ }^{68} \mathrm{Ga}$-DOTATOC PET/CT is performed. During all visits, laboratory investigations are performed to assess biochemical and hematological toxicity. Furthermore, patients will undergo physical examination and WHO performance status assessment.

\section{Objectives}

The primary objective is to evaluate whether there is a difference in $\mathrm{T} / \mathrm{N}$ activity concentration ratio on posttreatment SPECT/CT between the IA- and IV-treated liver lobes. As secondary objectives, activity concentration ratios and absolute mean values of tumor- and healthy liver-absorbed doses in the two lobes will be calculated and compared. Other secondary objectives include the post-treatment tumor response, dose-response relation, and post-treatment hepatic, hematologic, and renal toxicity. Activity concentration in contralateral liver tumors and extrahepatic tumor depositions and renal activity will also be assessed.

\section{Outcome assessment}

To determine the $\mathrm{T} / \mathrm{N}$ activity ratio on post-treatment SPECT/CT, volumes of interest (VOIs) are drawn based on the pre-treatment contrast-enhanced CT or magnetic resonance imaging (MRI) scan. Only tumors with a minimal diameter of $3 \mathrm{~cm}$ are delineated, up to three tumors per liver lobe. For the normal liver tissue VOIs, a representative portion of the normal liver tissue is delineated in each liver lobe, with a minimal diameter of $3 \mathrm{~cm}$. Of all delineated VOIs, the mean number of counts per voxel is calculated.

For the secondary endpoints, a dose-point kernel in commercially available software will be used to calculate the mean absorbed dose, based on the 24-h posttreatment SPECT/CT and mean effective half-life of ${ }^{177} \mathrm{Lu}$-DOTATATE $[20,21]$. Comparisons are made between the IA and IV groups by means of a Student $t$ test or Mann-Whitney $U$ test, where appropriate. Tumor response is assessed on contrast-enhanced CT or MRI 
using the Southwest Oncology Group (SWOG) solid tumor response criteria, Response Evaluation Criteria In Solid Tumors version 1.1 (RECIST 1.1) and modified Response Evaluation Criteria in Solid Tumors (mRECIST) [22-24]. Response to treatment is assessed on both the patient and liver levels. Moreover, biochemical response will be evaluated using chromogranin A (CgA) levels, measured at baseline and during follow-up. Biochemical, hematological, and clinical toxicity will be graded according to the Common Toxicity Criteria on Adverse Events (CTCAE) version 4.03 [25].

\section{Sample size assessment}

The intended sample size is calculated using a paired samples $t$ test on the difference in $\mathrm{T} / \mathrm{N}$ uptake ratio between the IA-treated and contralateral lobes, which is equivalent to a one-sample $t$ test on the within-patient difference scores. Assuming a moderate to large effect (i.e., Cohen's $\mathrm{d}_{z}=\mu_{\text {diff }} / \sigma_{\text {diff }}=0.65$ ), a one-sided $\alpha$ of 0.025 , and using a sequential testing procedure with an O'Brien-Fleming type error spending function, a power of approximately 0.9 is obtained with futility boundary values equal to $T_{1}=-0.1045056$ and $T_{2}=2.045732$ for an interim analysis at $\mathrm{n}_{1}=10$ and final analysis at $\mathrm{n}_{2}=$ 26. Interim analysis will therefore be performed after ten patients have been treated, and final analysis will be performed after 26 patients have been treated.

\section{Randomization}

For randomizing patients between left or right IA treatment, an online randomization tool is used to allow for multicenter access. The randomization algorithm is a computer-generated permuted block sequence with different block sizes. Due to the relatively small study sample $(n=26)$, only small blocks of size $=1$ and size $=2$ are used. No stratification is used.

\section{Statistical analysis}

Continuous variables, such as the primary outcome (i.e., $\mathrm{T} / \mathrm{N}$ ratio), will be described by means and standard deviations. The mean $\mathrm{T} / \mathrm{N}$ ratios will be compared between the IA- and IV-treated lobes by means of a paired $t$ test. Categorical variables, such as the response after treatment, will be compared by means of a chi-square or Fisher's exact test, depending on group size.

All statistical tests will be performed two-sided. A $p$ value of $<0.05$ will be considered statistically significant.

\section{Discussion}

Currently, many patients presenting with metastasized NETs experience significantly improved PFS and OS after treatment with ${ }^{177} \mathrm{Lu}$-DOTATATE. However, patients with diffuse and bulky liver metastases still have a worse prognosis and a lower disease control rate after treatment with PRRT, which leaves room for improvement of PRRT. The post hoc analysis of the NETTER-1 trial reported that the presence of bulky disease significantly limits median PFS after treatment with ${ }^{177} \mathrm{Lu}$ DOTATATE to 28 months, while the median PFS was not reached in 5 years of follow-up in patients with no bulky disease [14]. Of those patients with bulky disease, $70 \%$ had bulky liver disease. Earlier, Kwekkeboom et al. reported that a high hepatic tumor burden significantly reduced the median disease-specific survival from more than 48 months to only 25 months [13]. In line with their results, Ezziddin et al. reported a median OS of 43 months in patients with a hepatic tumor burden of more than $25 \%$, while median OS was not reached $(>70$ months) in patients with a hepatic tumor burden $<25 \%$ [12]. To increase the concentration of ${ }^{177} \mathrm{Lu}$-DOTATATE in intrahepatic tumors, IA administration may be an effective and relatively easy improvement to boost patient outcome. In the current study, the beneficial effect of IA ${ }^{177} \mathrm{Lu}$-DOTATATE will be studied in a controlled design.

To date, no prospective study on IA administration has been performed. A small number of studies, using different radiopharmaceuticals, have shown a beneficial effect [15]. The first study, performed by McStay et al., showed no additional toxicity when administering yttrium-90 ( $\left({ }^{90} \mathrm{Y}\right)$-DOTA-lanreotide IA [26]. In three publications by Limouris and colleagues, promising results were reported with response rates of $50 \%$ [27-29]. Kratochwil et al. found a partial response in $8 / 15$ patients and a complete response in $1 / 15$ patients after IA treatment with a combination of ${ }^{90} \mathrm{Y}$ and ${ }^{177} \mathrm{Lu}$-DOTATOC [30]. The same authors previously reported significantly enhanced tumor uptake of the diagnostic radiotracer ${ }^{68} \mathrm{Ga}$-DOTATOC after IA administration [31]. In a non-randomized crossoverlike study, they performed a ${ }^{68} \mathrm{Ga}$-DOTATOC PET/ CT after IV administration and, subsequently, a ${ }^{68} \mathrm{Ga}$ DOTATOC PET/CT after IA administration. Standardized uptake values in NETs were approximately 3.75 times higher after IA administration. Comparable enhancement of activity concentration in liver metastases was also shown by Pool et al., in a similar crossover-like study in three patients treated with indium-111-DTPA-octreotide, both IV and IA [32]. Up to a 2.4-fold higher concentration in tumors was quantified. In the available literature, no additional side effects were observed.

To our knowledge, the LUTIA study is the first RCT to investigate the effect of IA administration of ${ }^{177} \mathrm{Lu}$ DOTATATE in patients with NETs. Previously performed studies lacked comparison with IV administration. In the LUTIA study, a direct comparison can be 
made between IV and IA administration within the same patient. Consequently, between-patient differences have little to no effect on the difference in $\mathrm{T} / \mathrm{N}$ activity ratios. This is a great advantage of this study design with within-patient randomization, since NETs are known to be very heterogeneous. The heterogeneity of tumor characteristics (such as tumor subtype, growth rate, SSTR-2 expression, functional state, and imaging characteristics) causes difficulty when performing comparative research on NETs [33]. Within-patient comparison automatically corrects for any differences in tumor characteristics between patients. Furthermore, the paired design increases power in statistical analysis, and fewer patients need to be treated to notice an effect.

Multiple alternatives can be adopted in boosting treatment of NET liver metastases. For example, transarterial chemo or bland embolization (TACE/TAE) and radioembolization (TARE) are applied in loco-regional management of liver metastases. As liver metastases have a considerable effect on quality of life and survival, improving treatment of NET liver metastases has rightfully gained attention [34, 35]. Due to the multiple treatment strategies available, a patient-tailored approach is desirable. An increasingly used liver-directed therapy is TARE with ${ }^{90} \mathrm{Y}$-loaded glass or resin microspheres. Objective response rates of approximately $50 \%$ have been reported, and disease control is achieved in approximately $80 \%$ of patients with NETs [36-38]. The difference between TARE, TACE, and TAE is controversial, since similar PFS has been obtained. However, side effects are probably more likely to occur after TACE/TAE [1, 34, 39, 40]. Even though the most recent ENETS guidelines suggest that loco-regional therapies can be applied in the absence of extrahepatic disease, more and more studies suggest that there is room for radioembolization even though extrahepatic disease is present $[1,34,37,41]$. When extrahepatic disease is present, a combined or sequential application of TARE with PRRT might be of added value in the future [42-44].

There are some limitations to the current study. First, the number of subjects who will be included is rather small (i.e., 26). As a result, a small effect can possibly be missed. However, to justify the additional angiographic procedure and obtain a clinically relevant effect, the increase in $\mathrm{T} / \mathrm{N}$ ratio should be rather large. This increase will be noticeable with a study sample of 26 patients. Second, the second-pass effect used as a proxy for IV administration in this study might not be exactly the same as for regular IV administration, because a larger fraction of ${ }^{177} \mathrm{Lu}$-DOTATATE may be absorbed by IA-treated tumors. However, an excess of ${ }^{177} \mathrm{Lu}$-DOTATATE is administered (the same dose as in regular treatment) considering the relatively high urinary excretion of activity. This effect is therefore estimated to be negligible.
This study will provide insights in the IA administration of ${ }^{177} \mathrm{Lu}$-DOTATATE in a prospective and controlled design. The LUTIA study will investigate the potential benefit of IA administration of ${ }^{177} \mathrm{Lu}$-DOTATATE instead of conventional IV PRRT in patients with NET liver metastases. Increased activity concentration in liver metastases may lead to better response and survival. Positive study results will lead to a large RCT, investigating the long-term outcome of IA PRRT. Implementation of IA PRRT will need to be part of a personalized-medicine approach for the patient, so that only patients benefitting from IA PRRT will be treated.

\section{Trial status}

Patient recruitment was ongoing at the time of submission. The protocol version is 3.0; recruitment started on 27 June 2018; estimated completion of recruitment will be achieved in the third quarter of 2020 .

\section{Supplementary information}

Supplementary information accompanies this paper at https://doi.org/10. 1186/s13063-019-3888-0.

Additional file 1. Standard Protocol Items: Recommendations for Interventional Trials (SPIRIT) 2013 checklist: recommended items to address in a clinical trial protocol and related documents.

\section{Abbreviations \\ ${ }^{177}$ Lu-DOTATATE: Lutetium-177-DOTA-octreotate; ${ }^{90}$ Y: Yttrium-90; CBCT: Cone-beam computed tomography; CgA: Chromogranin A; CTCAE: Common Toxicity Criteria on Adverse Events; ENETS: European Neuroendocrine Tumor Society; IA: Intra-arterial; IV: Intravenous; LUTIA: Lutetium Intra-Arterial; mRECIST: Modified Response Evaluation Criteria In Solid Tumors; NET: Neuroendocrine tumor; OS: Overall survival; PET/ CT: Positron emission tomography/computed tomography; PFS : Progression-free survival; PRRT: Peptide receptor radionuclide therapy; RCT: Randomized controlled trial; RECIST 1.1: Response Evaluation Criteria In Solid Tumors version 1.1; SPECT/CT: Single photon emission computed tomography/computed tomography; SSTR-2: Somatostatin receptor subtype 2; SWOG: Southwest Oncology Group; T/N: Tumor-to-non-tumor; \\ TACE: Trans-arterial chemoembolization; TAE: Trans-arterial embolization; TARE: Trans-arterial radioembolization; VOI: Volume of interest; WHO: World Health Organization}

\section{Acknowledgements}

Not applicable.

\section{Authors' contributions}

SCE, AJATB, AM, MPMS, MGEHL, and MWB were involved in the trial design, project development, and drafting of the study protocol manuscript. AJATB, $M G E H L, M W B, A M$, and MPMS perform the patient evaluation and treatment. SCE collects the clinical data and will perform the statistical analysis. MGEHL is the principal investigator for the trial. All authors read and approved the final manuscript.

\section{Funding}

The therapeutic drug used in the LUTIA study (Lutathera ${ }^{\circledast}$ ) is provided free of charge by AAA/Novartis, Saint-Genis-Pouilly, France. The collaboration project is financed by the Ministry of Economic Affairs and Climate Policy by means of the PPP Allowance made available by the Top Sector Life Sciences \& Health to stimulate public-private partnerships.

Availability of data and materials Not applicable. 


\section{Ethics approval and consent to participate}

The LUTIA study is approved by the Institutional Review Board of the University Medical Center Utrecht (reference number 17-446), and all participants provide written informed consent to participate.

\section{Consent for publication}

Not applicable.

\section{Competing interests}

The authors declare that they have no competing interests.

Received: 28 August 2019 Accepted: 5 November 2019 Published online: 05 February 2020

\section{References}

1. Pavel M, OToole D, Costa F, et al. ENETS Consensus Guidelines update for the management of distant metastatic disease of intestinal, pancreatic, bronchial neuroendocrine neoplasms (NEN) and NEN of unknown primary site. Neuroendocrinology. 2016;103(2):172-85. https://doi.org/10.1159/000443167.

2. Kaltsas GA, Besser GM, Grossman AB. The diagnosis and medical management of advanced neuroendocrine tumors. Endocr Rev. 2004;25(3): 458-511. https://doi.org/10.1210/er.2003-0014.

3. Lepage C, Bouvier AM, Faivre J. Endocrine tumours: epidemiology of malignant digestive neuroendocrine tumours. Eur J Endocrinol. 2013;168(4): R77-83. https://doi.org/10.1530/EJE-12-0418.

4. Niederle MB, Hackl M, Kaserer K, Niederle B. Gastroenteropancreatic neuroendocrine tumours: the current incidence and staging based on the $\mathrm{WHO}$ and European Neuroendocrine Tumour Society classification: an analysis based on prospectively collected parameters. Endocr Relat Cancer. 2010;17(4):909-18. https://doi.org/10.1677/ERC-10-0152.

5. Strosberg J, El-Haddad G, Wolin E, et al. Phase 3 trial of ${ }^{177}$ Lu-Dotatate for midgut neuroendocrine tumors. N Engl J Med. 2017;376(2):125-35. https:// doi.org/10.1056/NEJMoa1607427.

6. Delpassand ES, Samarghandi A, Zamanian S, et al. Peptide receptor radionuclide therapy with ${ }^{177}$ Lu-DOTATATE for patients with somatostatin receptor-expressing neuroendocrine tumors. Pancreas. 2014;43(4):518-25. https://doi.org/10.1097/MPA.0000000000000113.

7. Kam BLR, Teunissen JJM, Krenning EP, et al. Lutetium-labelled peptides for therapy of neuroendocrine tumours. Eur J Nucl Med Mol Imaging. 2012; 39(S1):103-12. https://doi.org/10.1007/s00259-011-2039-y.

8. Dash A, Pillai MRA, Knapp FF. Production of ${ }^{177} \mathrm{Lu}$ for targeted radionuclide therapy: available options. Nucl Med Mol Imaging. 2015;49(2):85-107. https://doi.org/10.1007/s13139-014-0315-z.

9. Brabander T, van der Zwan WA, Teunissen JJM, et al. Long-term efficacy, survival, and safety of [ ${ }^{177}$ Lu-DOT $\left.{ }^{0}, \mathrm{Tyr}^{3}\right]$ octreotate in patients with gastroenteropancreatic and bronchial neuroendocrine tumors. Clin Cancer Res. 2017;23(16):4617-24. https://doi.org/10.1158/1078-0432.CCR-16-2743.

10. Sabet A, Dautzenberg $K$, Haslerud T, et al. Specific efficacy of peptide receptor radionuclide therapy with ${ }^{177}$ Lu-octreotate in advanced neuroendocrine tumours of the small intestine. Eur J Nucl Med Mol Imaging. 2015;42(8):1238-46. https://doi.org/10.1007/s00259-015-3041-6.

11. Ezziddin S, Khalaf F, Vanezi M, et al. Outcome of peptide receptor radionuclide therapy with $177 \mathrm{Lu}$-octreotate in advanced grade 1/2 pancreatic neuroendocrine tumours. Eur J Nucl Med Mol Imaging. 2014; 41(5):925-33. https://doi.org/10.1007/s00259-013-2677-3.

12. Ezziddin S, Attassi M, Yong-Hing CJ, et al. Predictors of long-term outcome in patients with well-differentiated gastroenteropancreatic neuroendocrine tumors after peptide receptor radionuclide therapy with 177Lu-Octreotate. J Nucl Med. 2014;55(2):183-90. https://doi.org/10.2967/jnumed.113.125336.

13. Kwekkeboom DJ, de Herder WW, Kam BL, et al. Treatment with the radiolabeled somatostatin analog [ ${ }^{177} \mathrm{Lu}$-DOTA ${ }^{0}, \mathrm{Tyr}^{3}$ ] octreotate: toxicity, efficacy, and survival. J Clin Oncol. 2008;26(13):2124-30. https://doi.org/10. 1200/JCO.2007.15.2553.

14. Strosberg J, Hendifar A, Yao JC, et al. Impact of liver tumor burden on therapeutic effect of ${ }^{177}$ Lu-dotatate treatment in NETTER-1 study. Ann Oncol. 2018;29(Suppl 8):1316P. https://doi.org/10.1093/annonc/mdy293.009.

15. Ebbers S, Barentsz M, Braat A, Lam M. Intra-arterial peptide receptor radionuclide therapy for neuroendocrine tumor liver metastases. Dig Dis Interv. 2019;03(1):081-90. https://doi.org/10.1055/s-0038-1676300.
16. Cornu C, Kassai B, Fisch R, et al. Experimental designs for small randomised clinical trials: an algorithm for choice. Orphanet J Rare Dis. 2013:8(1):48. https://doi.org/10.1186/1750-1172-8-48.

17. Chan A-W, Tetzlaff JM, Altman DG, et al. SPIRIT 2013 Statement: defining standard protocol items for clinical trials. Ann Intern Med. 2013;158(3):200. https://doi.org/10.7326/0003-4819-158-3-201302050-00583.

18. Klöppel G, Couvelard A, Perren A, et al. ENETS consensus guidelines for the standards of care in neuroendocrine tumors: towards a standardized approach to the diagnosis of gastroenteropancreatic neuroendocrine tumors and their prognostic stratification. Neuroendocrinology. 2009;90(2): 162-6. https://doi.org/10.1159/000182196.

19. Advanced Accelerator Applications. Summary of product characteristics. 2017. https://euhcp.lutathera.com/.

20. Kupitz D, Wetz C, Wissel H, et al. Software-assisted dosimetry in peptide receptor radionuclide therapy with ${ }^{177}$ Lutetium-DOTATATE for various imaging scenarios. PLoS One. 2017;12(11):e0187570. https://doi.org/10.1371/journal.pone.0187570.

21. Li T, Ao ECl, Lambert B, Brans B, Vandenberghe S, Mok GSP. Quantitative imaging for targeted radionuclide therapy dosimetry - technical review. Theranostics. 2017;7(18):4551-65. https://doi.org/10.7150/thno.19782.

22. Green S, Weiss GR. Southwest Oncology Group standard response criteria, endpoint definitions and toxicity criteria. Investig New Drugs. 1992;10(4): 239-53. https://doi.org/10.1007/BF00944177.

23. Eisenhauer EA, Therasse $P$, Bogaerts J, et al. New response evaluation criteria in solid tumours: Revised RECIST guideline (version 1.1). Eur J Cancer. 2009; 45(2):228-47. https://doi.org/10.1016/j.ejca.2008.10.026.

24. Lencioni R, Llovet J. Modified RECIST (mRECIST) assessment for hepatocellular carcinoma. Semin Liver Dis. 2010;30(01):052-60. https://doi. org/10.1055/s-0030-1247132.

25. National Cancer Institute. Common terminology criteria for adverse events version 4.03. 2009. https://www.eortc.be/services/doc/ctc/CTCAE_4.03_201006-14_QuickReference_5x7.pdf. Published 2014. Accessed 5 June 2019.

26. McStay MKG, Maudgil D, Williams M, et al. Large-volume liver metastases from neuroendocrine tumors: hepatic intraarterial 90 Y-DOTA-Lanreotide as effective palliative therapy. Radiology. 2005;237(2):718-26. https://doi.org/10. 1148/radiol.2372041203.

27. Limouris GS, Karfis I, Chatzioannou A, et al. Super-selective hepatic arterial infusions as established technique ("ARETAIEION" protocol) of [177Lu]DOTATATE in inoperable neuroendocrine liver metastases of gastro-enteropancreatic (GEP) tumors. Q J Nucl Med Mol Imaging. 2012;56(6):551-8.

28. Limouris GS, Poulantzas V, Trompoukis N, et al. Comparison of 111 ln[DTPA0]octreotide versus non carrier added 177Lu- [DOTA0,Tyr3]-octreotate efficacy in patients with GEP-NET treated intra-arterially for liver metastases. Clin Nucl Med. 2016;41(3):194-200. https://doi.org/10.1097/RLU.0000000000001096.

29. Limouris GS, Chatziioannou A, Kontogeorgakos D, et al. Selective hepatic arterial infusion of In-111-DTPA-Phe1-octreotide in neuroendocrine liver metastases. Eur J Nucl Med Mol Imaging. 2008;35(10):1827-37. https://doi. org/10.1007/s00259-008-0779-0.

30. Kratochwil C, López-Benítez R, Mier W, et al. Hepatic arterial infusion enhances DOTATOC radiopeptide therapy in patients with neuroendocrine liver metastases. Endocr Relat Cancer. 2011;18(5):595-602. https://doi.org/10. 1530/ERC-11-0144.

31. Kratochwil C, Giesel FL, Lopez-Benitez R, et al. Intraindividual comparison of selective arterial versus venous 68Ga-DOTATOC PET/CT in patients with gastroenteropancreatic neuroendocrine tumors. Clin Cancer Res. 2010; 16(10):2899-905. https://doi.org/10.1158/1078-0432.CCR-10-0004.

32. Pool SE, Kam BLR, Koning GA, et al. [111 In-DTPA]octreotide tumor uptake in GEPNET liver metastases after intra-arterial administration: an overview of preclinical and clinical observations and implications for tumor radiation dose after peptide radionuclide therapy. Cancer Biother Radiopharm. 2014; 29(4):179-87. https://doi.org/10.1089/cbr.2013.1552.

33. Modlin IM, Oberg K, Chung DC, et al. Gastroenteropancreatic neuroendocrine tumours. Lancet Oncol. 2008;9(1):61-72. https://doi.org/10. 1016/S1470-2045(07)70410-2.

34. de Mestier L, Zappa M, Hentic O, Vilgrain V, Ruszniewski P. Liver transarterial embolizations in metastatic neuroendocrine tumors. Rev Endocr Metab Disord. 2017;18(4):459-71. https://doi.org/10.1007/s11154-017-9431-2.

35. Frilling A, Clift AK. Therapeutic strategies for neuroendocrine liver metastases. Cancer. 2015;121(8):1172-86. https://doi.org/10.1002/cncr.28760.

36. Jia Z, Wang W. Yttrium-90 radioembolization for unresectable metastatic neuroendocrine liver tumor: a systematic review. Eur J Radiol. 2018. https:// doi.org/10.1016/j.ejrad.2018.01.012. 
37. Braat AJAT, Kappadath SC, Ahmadzadehfar H, et al. Radioembolization with $90 \mathrm{Y}$ resin microspheres of neuroendocrine liver metastases: international multicenter study on efficacy and toxicity. Cardiovasc Intervent Radiol. 2019; 42(3):413-25. https://doi.org/10.1007/s00270-018-2148-0.

38. Devcic Z, Rosenberg J, Braat AJA, et al. The efficacy of hepatic $90 \mathrm{Y}$ resin radioembolization for metastatic neuroendocrine tumors: a meta-analysis. J Nucl Med. 2014;55(9):1404-10. https://doi.org/10.2967/jnumed.113.135855.

39. Do Minh D, Chapiro J, Gorodetski B, et al. Intra-arterial therapy of neuroendocrine tumour liver metastases: comparing conventional TACE, drug-eluting beads TACE and yttrium-90 radioembolisation as treatment options using a propensity score analysis model. Eur Radiol. 2017;27(12): 4995-5005. https://doi.org/10.1007/s00330-017-4856-2.

40. Chen JX, Rose S, White SB, et al. Embolotherapy for neuroendocrine tumor liver metastases: prognostic factors for hepatic progression-free survival and overall survival. Cardiovasc Intervent Radiol. 2017;40(1):69-80. https://doi. org/10.1007/s00270-016-1478-z.

41. Frilling $A$, Modlin IM, Kidd M, et al. Recommendations for management of patients with neuroendocrine liver metastases. Lancet Oncol. 2014; 15(1):e8-21. https://doi.org/10.1016/S1470-2045(13)70362-0.

42. Maccauro M, Follacchio GA, Spreafico C, Coppa J, Seregni E. Safety and efficacy of combined peptide receptor radionuclide therapy and liver selective internal radiation therapy in a patient with metastatic neuroendocrine tumor. Clin Nucl Med. 2019;44(4):e286-8. https://doi.org/10. 1097/RLU.0000000000002480.

43. Filippi L, Ciorra A, Sardella B, Schillaci O, Bagni O. Sequential use of (90)Y microspheres radioembolization and (177)Lu-Dotatate in pluri-metastatic neuroendocrine tumors: a case report. Nucl Med Mol Imaging (2010). 2014; 48(4):321-5. https://doi.org/10.1007/s13139-014-0292-2.

44. Ezziddin S, Meyer C, Kahancova S, et al. 90Y Radioembolization after radiation exposure from peptide receptor radionuclide therapy. J Nucl Med. 2012;53(11):1663-9. https://doi.org/10.2967/jnumed.112.107482.

\section{Publisher's Note}

Springer Nature remains neutral with regard to jurisdictional claims in published maps and institutional affiliations.

Ready to submit your research? Choose BMC and benefit from:

- fast, convenient online submission

- thorough peer review by experienced researchers in your field

- rapid publication on acceptance

- support for research data, including large and complex data types

- gold Open Access which fosters wider collaboration and increased citations

- maximum visibility for your research: over $100 \mathrm{M}$ website views per year

At $\mathrm{BMC}$, research is always in progress.

Learn more biomedcentral.com/submissions 